\section{LA-UR-97-2756 \\ July 1997}

\section{RECEVED \\ NOV 031997 \\ OSTI}

\title{
LOS ALAMOS NEUTRON SCIENCE CENTER AREA-A BEAM WINDOW HEAT TRANSFER ANALYSIS
}

by

David I. Poston

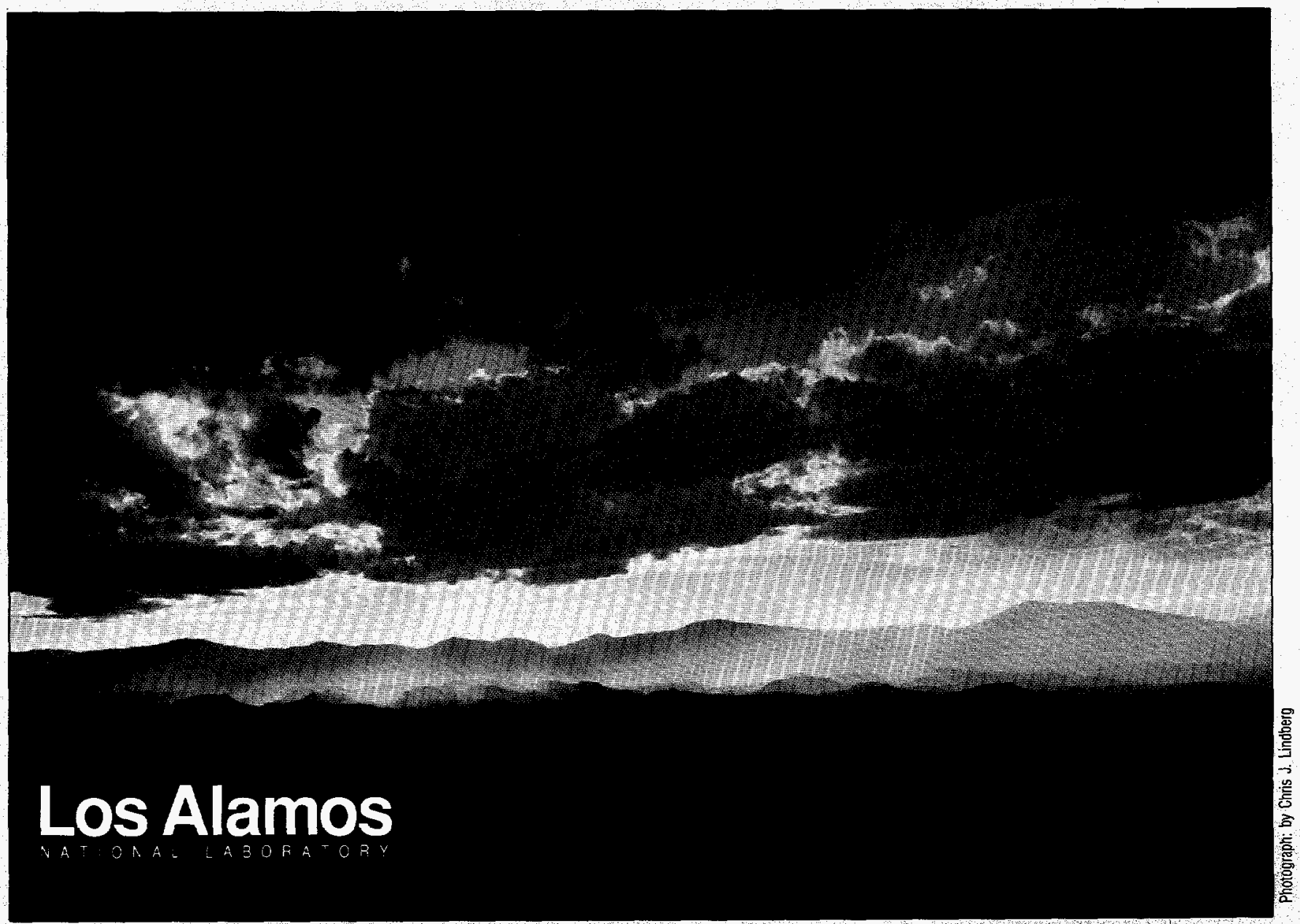

Los Alamos National Laboratory, an affirmative action/equal opportunity employer, is operated by the University of California for the U.S. Department of Energy under contract W-7405-ENG-36. By acceptance of this article, the publisher recognizes that the US.S. Govemment retains a nonexclusive, myalty-free license to publish or reproduce the published form of this contribution, or to allow others to do so, for U.S. Government purposes. The Los Alamos National taboratory requests that the publisher identify this article as work performed under the auspices of the U.S. Department of Energy. Los Alamos National Laboratory strengly supports academic freedom and a researcher's right b Dublish: therefore. the Laboratorv as an institution does not endorse the viewooint of a oublication or guarantee its technical correctness. 


\section{DISCLAMMER}

Portions of this docoment may be illegible in electronic image products. Images are produced from the best available original docomentert. 


\title{
LOS ALAMOS NEUTRON SCIENCE CENTER AREA-A BEAM WINDOW HEAT TRANSFER ANALYSIS
}

\author{
David Poston \\ Nuclear Systems Design and Analysis Group \\ Technology and Safety Assessment Division \\ Los Alamos National Laboratory
}

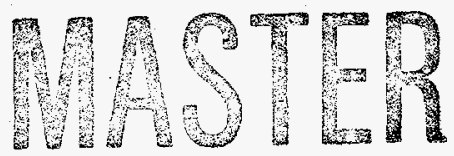

July 1997

\section{DISCLAIMER}

This report was prepared as an account of work sponsored by an agency of the United States Government. Neither the United States Government nor any agency thereof, nor any of their employees, makes any warranty, express or implied, or assumes any legal liability or responsibility for the accuracy, completeness, or usefulness of any information, apparatus, product, or process disclosed, or represents that its use would not infringe privately owned rights. Reference herein to any specific commercial product, process, or service by trade name, trademark, manufacturer, or otherwise does not necessarily constitute or imply its endorsement, recommendation, or favoring by the United States Government or any agency thereof. The views and opinions of authors expressed herein do not necessarily state or reflect those of the United States Government or any agency thereof.

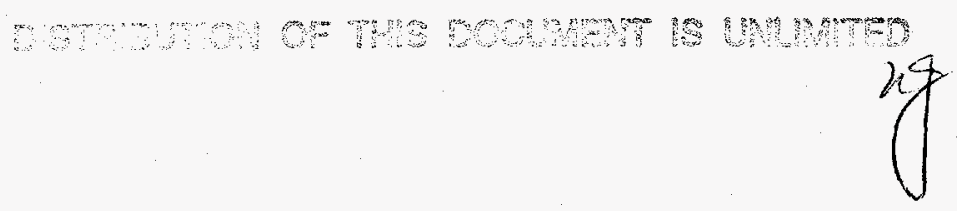




\section{EXECUTIVE SUMMARY}

The primary purpose of this analysis was to help determine if the Area-A beam window could handle the accelerator production of tritium materials test beam, which has a current of $1 \mathrm{~mA}$ and a beam width $(2 \sigma)$ of $3.0 \mathrm{~cm}$. It was found the window temperatures are within acceptable limits given this beam profile. The peak window temperature is calculated to be $379^{\circ} \mathrm{C}$ (possibly $\sim 400^{\circ} \mathrm{C}$, considering the variance in the power density and the uncertainty in the flow rate, and possibly much higher if an oxide layer is present), and coolant margins to boiling are adequate. The temperature calculations were also used in conjunction with stress calculations by R. Parker. ${ }^{1}$ Parker found that the stresses in the window are moderately high $(\sim 70 \%$ of yield $)$. The window should survive the proposed conditions; however, if the beam peak current density is increased, the window is in definite jeopardy. Therefore, great care must be taken to ensure that the beam width does not fall below the specified $2 \sigma$ of $3 \mathrm{~cm}$.

Another goal of the study was to determine what, if any, information could be drawn from the window thermocouples (TCs), and what limits should be placed on maximum TC temperatures. It was found that the TCs read several times higher than the calculated window temperature because of the heating of the TCs themselves. The TCs read a temperature difference $\left(T_{T C}-T_{\text {cool }}\right)$ more than four times greater than the calculated window temperature difference $\left(T_{\text {win }}-T_{\text {cool }}\right)$, where $T_{\text {win }}$ is the outer surface temperature of the window and $T_{\text {cool }}$ is the bulk coolant temperature. Based on this information, it was concluded that the current window TC temperature limit of $900^{\circ} \mathrm{C}$ could be raised significantly. In fact, the TC temperature limit must be raised significantly; the inner-ring TCs should read in the range of 1200 to $1450^{\circ} \mathrm{C}$ in the $1-\mathrm{mA}, 3-\mathrm{cm}$ beam; and some could read higher if the beam is off-center. There is a good chance that the inner TCs will fail before these temperatures are reached, leaving only the outer TCs for beam diagnostics. Furthermore, it will be very difficult to use the outer TCs as a safety trip mechanism because if the beam gets tighter (causing maximum temperatures to rise), the temperatures at these outer locations go down. It may be desirable to design new TCs that are of smaller diameter and/or are more efficiently attached to the window. The other option would be to consider optical measuring techniques.

An unexpected finding of this study was that the Area-A beam width was significantly larger than the harp-wire estimate in the past. Several datapoints were analyzed, and it was concluded than the actual beam width was 20 to $25 \%$ greater than the harp-wire printout suggests. The data from the harp wire itself were not in question; rather, it was the fitting technique applied to the data that was questionable. This is a very important issue because the dose to peak samples in the beam could be 30 to $40 \%$ lower than expected, whereas the dose to peripheral samples could be significantly greater than expected. As of April 1997, this conclusion was acknowledged and the problem addressed.

The effect of a possible copper-oxide layer on the window coolant passage is also examined briefly. A large (>10 mil) copper-oxide layer buildup would significantly affect heat transfer. A 1/32-in. oxide layer would cause a $>150^{\circ} \mathrm{C}$ maximum temperature increase for a $1-\mathrm{mA}, 3-\mathrm{cm}$ beam, which would put significantly more thermal stress on the window and possibly put the window in jeopardy. A crude analysis of window TC readings over the life of the window showed no evidence of a large oxide buildup, although the study is by no means conclusive. The fact that a substantial copper-oxide layer has been seen on Inconel structures in the past carries significantly more weight than does this analysis.

Finally, in performing this analysis it was noted that the TC readings for the April 1997 beam run were much lower than expected. The lower readings possibly could be because of a leak that was diagnosed in the cooling system (potentially spraying onto the outside of the window) or because almost all of the TCs are no longer working properly. Whatever the reason, the readings are so low that this issue should be investigated to ensure that the current is as high as advertised. 


\section{CONTENTS}

EXECUTIVE SUMMARY

ABSTRACT.

INTRODUCTION

BEAM CHARACTERIZATION

POWER DEPOSITION

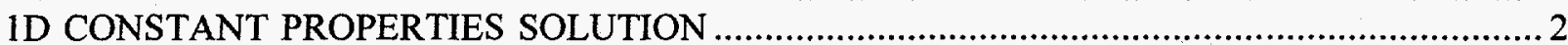

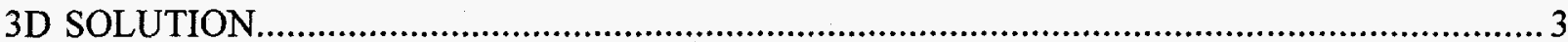

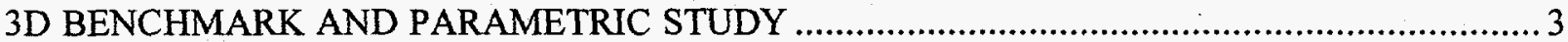

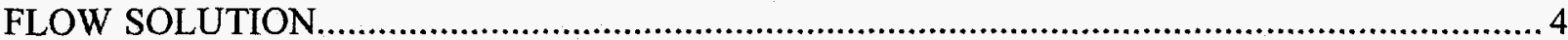

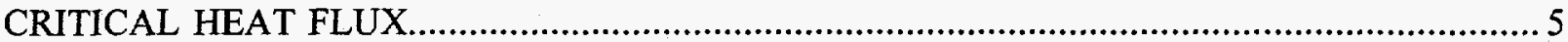

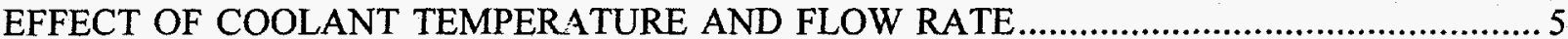

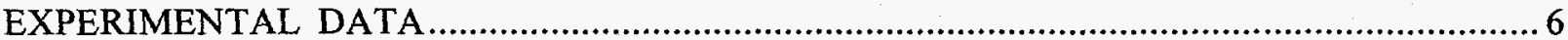

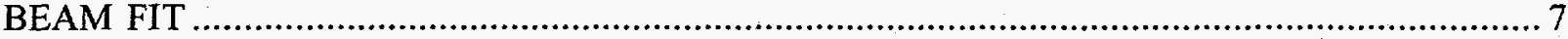

WINDOW TEMPERATURES AS A FUNCTION OF BEAM CURRENT AND WIDTH............8

PREDICTED WINDOW AND THERMOCOUPLE TEMPERATURES FOR A 1-MA BEAM ......9

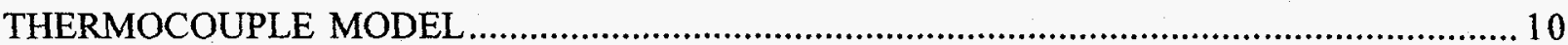

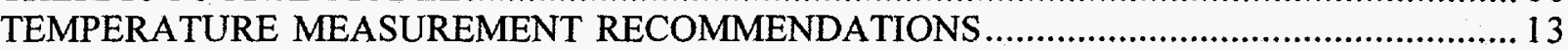

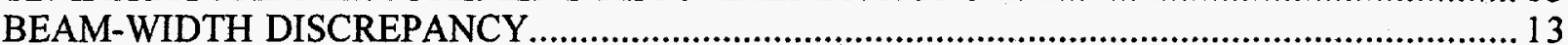

POSSIBLE OXIDE LAYER BUILDUP WINDOW COOLANT PASSAGE $\ldots \ldots \ldots \ldots \ldots \ldots \ldots \ldots \ldots \ldots . . . . . . . . . . . . . . .14$

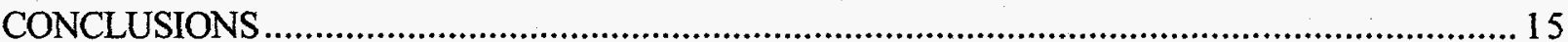

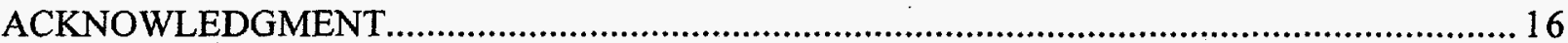

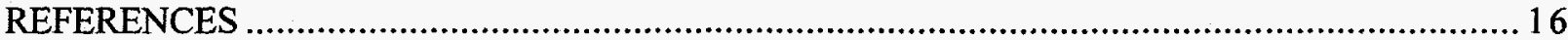

APPENDIX A. A PHOTO OF AREA-A WINDOW AND THERMOCOUPLES ..................... A-1

TABLES

TABLE 1 EFFECT OF CALCULATION ASSUMPTIONS ON 3D TEMPERATURE

NORMALIZED

TABLE 2 COMPARISON OF CALCULATED AND MEASURED RESULTS OF NORMALIZED TEST DATA AT $700 \mu$ A AND A COOLANT FLOW OF 3 gpm AT $20^{\circ} \mathrm{C}$

TABLE 3 EFFECT OF BEAM CURRENT AND WIDTH ON WINDOW TEMPERATURES ... 10

TABLE 4 PREDICTED WINDOW AND THERMOCOUPLE TEMPERATURES FOR A 1-mA BEAM

TABLE 5 THERMOCOUPLE $\triangle T\left(T_{T C}-T_{\text {WIN }} I^{\circ}{ }^{\circ} \mathrm{C}\right)$ FOR VARIOUS SURFACE CONDUCTIVITIES AT THE CENTER OF A 1-mA/3-cm BEAM …..................... 12

TABLE 6 BEAM-WIDTH PREDICTIONS OF VARIOUS METHODS ................................. 13

TABLE 7 TC MULTIPLIER VS WINDOW EXPOSURE .................................................. 15

\section{FIGURES}

Fig. 1 Average TC readings for each ring as a function of beam current .............................. 6

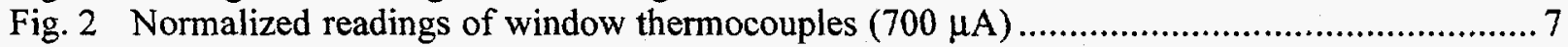

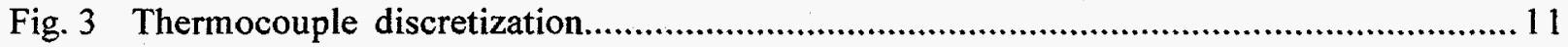




\title{
LOS ALAMOS NEUTRON SCIENCE CENTER AREA-A BEAM WINDOW HEAT TRANSFER ANALYSIS
}

\author{
David Poston
}

\begin{abstract}
Several analyses that investigate heat transfer in the Area-A beam window were conducted. We found that the Area-A window should be able to withstand the $1-\mathrm{mA}$, $3-\mathrm{cm}$ beam of the accelerator production of tritium materials test, but that the margins to failure are small. We also determined that when the window is subjected to the $1-\mathrm{mA}, 3-\mathrm{cm}$ beam, the inner window thermocouples should read higher than the current temperature limit of $900^{\circ} \mathrm{C}$, although it is possible that the thermocouples may fail before they reach these temperatures. Another finding of this study was that the actual beam width before April 1997 was 20 to $25 \%$ greater than the harp-wire printout indicated. Finally, the effect of a copper-oxide layer on the window coolant passage was studied. The results did not indicate the presence a large copper-oxide layer; however, the results were not conclusive.
\end{abstract}

\section{INTRODUCTION}

The Area-A beam window consists of two Inconel hemispheres and water flows through a gap between these two shells. Several thermocouples (TCs) are attached to the outside surface of the window; however, their readings are questionable because they lie in the path of the beam. Therefore, there is considerable $\Delta \mathrm{T}$ within the TCs themselves (the "thermocouple" is actually a TC unit that includes the TC, the sheath and insulation, and the tab used to weld the unit to the window; it is simply referred to as the TC in this report). The accelerator production of tritium (APT) materials testing program proposes using a higher power density beam than the window has normally seen in the past. This study was undertaken to determine what effect this may have on the window and to determine what information can be obtained from the TCs and the temperature limits that should be placed on them. The calculations in this report are limited to the outer hemisphere because (1) this is where the TCs are placed, (2) it is slightly thicker that the inner shell, (3) and inward radial heat flow produces larger temperature gradients than outward radial heat flow because the area is decreasing.

\section{BEAM CHARACTERIZATION}

The beam is assumed to be a two-dimensional Gaussian distribution, which can be offset from the window centerline. This offset can be the result of the off-centering of the beam axis and/or the "wiggler," which rotates the beam about the beam axis with a fixed radius and frequency. The equation describing the beam is

$$
i(x, y)=i_{0} \exp \left(-\frac{\left(x-x_{0}-x_{w i g}\right)^{2}}{2 \sigma_{x}^{2}}-\frac{\left(y-y_{0}-y_{w i g}\right)^{2}}{2 \sigma_{y}^{2}}\right) \quad \text { where: } i_{0}=\frac{I_{\text {tot }}}{2 \pi \sigma_{x} \sigma_{y}} .
$$

In the above equation, $\sigma_{\mathrm{x}}$ and $\sigma_{\mathrm{y}}$ are the beam widths, $\mathrm{x}_{0}$ and $\mathrm{y}_{0}$ are the offset of the beam axis from the window centerline, $x_{\text {wig }}$ and $y_{\text {wig }}$ are the position of the wiggler as defined by $x_{\text {wig }}=r_{\text {wig }} \cos \left(\phi_{\text {wig }}\right)$ and $y_{\text {wig }}=r_{\text {wig }} \sin \left(\phi_{\text {wig }}\right)\left(\phi_{\text {wig }}\right.$ is determined by the wiggler frequency and the time), and $I_{\text {tot }}$ is the total beam current. 
If only the average and not the transient effect of the wiggler is modeled, then the above equation is integrated over $0<\phi_{\text {wig }}<2 \pi$ to get the average current seen by a specific location.

The beam halo is neglected in this analysis. C. Pillai estimated that $<0.5 \%$ of the beam current would be in the halo or outside of the Gaussian distribution. ${ }^{2}$ Currently, there are no diagriostic devices on site to measure the halo.

There are two targets upstream of the window, the A1 and A2 targets. T. Newlin stated that when in the beamline, the A1 and A2 targets reduce window current by about 8 and $12 \%$, respectively. ${ }^{3}$ For the first round of the APT material tests, beginning in August 1996, Pillai ${ }^{2}$ stated that the A2 target would be in place for 1 month (probably October) of the 4-month operating period. The effect of the $\mathrm{A} 1$ and $\mathrm{A} 2$ targets on the geometric profile of the beam is not studied in this report.

\section{POWER DEPOSITION}

The power density at a given location is determined by the current density and the effective power deposition factor $\mathrm{dE} / \mathrm{dx}$. The majority of power deposition results from protons and is defined by the "coulomb" $\mathrm{dE} / \mathrm{dx}$ (this is the number quoted in most references). The "effective" $\mathrm{dE} / \mathrm{dx}$ also includes power deposition resulting from nuclear interactions and radiation exchange with other regions of the system. The effective $\mathrm{dE} / \mathrm{dx}$ for this study is based on power depositions calculated by $\mathrm{P}$. Ferguson with the LAHET/MCNP code.

The coulomb $\mathrm{dE} / \mathrm{dx}$ is relatively constant for nickel (the primary component of Inconel) over the proton energy range considered $(15.417 \mathrm{MeV} / \mathrm{cm}$ at a proton energy of $760 \mathrm{MeV}$, and $15.211 \mathrm{MeV} / \mathrm{cm}$ at a proton energy of $800 \mathrm{MeV}$ ). The thickness of the window (both hemispheres) is $<0.5 \mathrm{~cm}$ so that the proton should lose $<8 \mathrm{MeV}$; thus, $\mathrm{dE} / \mathrm{dx}$ certainly can be assumed to be constant over the range of the window. A value of $15.23 \mathrm{MeV} / \mathrm{cm}$ would give a maximum power density of $1077 \mathrm{~W} / \mathrm{cm}^{3}$ for a $1-\mathrm{mA}, 3-\mathrm{cm}$ beam. From the P. Ferguson data, a best estimate of peak power density is $\sim 1260 \mathrm{~W} / \mathrm{cm}^{3}$, which gives an effective $\mathrm{dE} / \mathrm{dx}$ of 17.82 . Based on the relative error of this calculation, a somewhat conservative limit of $1320 \mathrm{~W} / \mathrm{cm}^{3}$ can be set on the peak power density, giving a loosely bounding $\mathrm{dE} / \mathrm{dx}$ of 18.67 . The best-estimate $\mathrm{dE} / \mathrm{dx}$ is used for the data fitting and TC predictions.

\section{D CONSTANT PROPERTIES SOLUTION}

The easiest way to obtain maximum window temperature is to assume that the window is an infinite flat plate of thickness $t$. In this case, the film temperature rise $\left(T_{\text {inner }}-T_{\text {cool }}\right)$ and the window temperature rise $\left(T_{\text {outer }}-T_{\text {inner }}\right)$ are

$$
\Delta T_{f i l m}=\frac{q^{\prime \prime}}{h}=\frac{\dddot{Q} t}{h} \quad \text { and } \quad \Delta T_{\text {win }}=\frac{\dddot{Q} t^{2}}{2 k} .
$$

For $\mathrm{t}=0.236 \mathrm{~cm}, \mathrm{~h}=24000 \mathrm{~W} / \mathrm{m}^{2 \circ} \mathrm{C}, \mathrm{k}=11.2 \mathrm{~W} / \mathrm{m}-{ }^{\circ} \mathrm{C}$ (Inconel $@ 30^{\circ} \mathrm{C}$ ), and $\dddot{\mathrm{Q}}=1260 \mathrm{~W} / \mathrm{cm}^{3}$ (corresponding to the beam centerline at $1 \mathrm{~mA}$ and $2 \sigma=3 \mathrm{~cm}$ ), which gives

$$
\mathrm{q}^{\prime \prime}=2.97 \mathrm{MW} / \mathrm{m}^{2}, \Delta \mathrm{T}_{\text {film }}=123.9^{\circ} \mathrm{C}, \Delta \mathrm{T}_{\mathrm{win}}=313.3^{\circ} \mathrm{C}
$$

To account for the curvature of the window, a simple one-dimensional (1D) solution can be obtained in spherical coordinates:

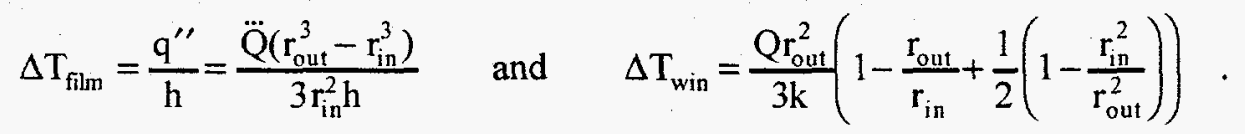


For $r_{\text {out }}=10.160 \mathrm{~cm}$ and $r_{\text {in }}=9.924 \mathrm{~cm}$, this gives

$$
\begin{aligned}
& q "=3.04 \mathrm{MW} / \mathrm{m}^{2}, \\
& \Delta \mathrm{T}_{\text {filin }}=\quad 126.8^{\circ} \mathrm{C},
\end{aligned}
$$

and

$$
\Delta \mathrm{T}_{\text {win }}=318.2^{\circ} \mathrm{C}
$$

This is slightly higher than the flat plate solution because the heat transfer area gets smaller as the heat flow moves inward.

\section{D SOLUTION}

When the above 1D models are applied to the experimental TC data, the outer-ring TC readings were much higher than expected for the given beam dimensions. A three-dimensional (3D) model was developed with the expectation of quantifying this discrepancy. The conduction equation is solved in spherical coordinates:

$$
\begin{aligned}
& \rho C p \frac{\partial T}{\partial t}=-\nabla \cdot q+\dddot{Q} \quad \text { or } \quad \rho C p \frac{\partial T}{\partial t}=\nabla \cdot(k \nabla T)+\dddot{Q} \\
& \text { where: } \quad \nabla \cdot(k \nabla T)=\frac{1}{r^{2}} \frac{\partial}{\partial r}\left(r^{2} k \frac{\partial T}{\partial r}\right)+\frac{1}{r^{2} \sin \theta} \frac{\partial}{\partial \theta}\left(\sin \theta k \frac{\partial T}{\partial \theta}\right)+\frac{1}{r^{2} \sin ^{2} \theta} \frac{\partial}{\partial \phi}\left(k \frac{\partial T}{\partial \phi}\right) .
\end{aligned}
$$

The transient solution is solved primarily as a means to iterate to the steady-state value, although it is also useful in qualifying the time scales of temperature changes and the periodic effect of the wiggler. A FORTRAN code called WIN3D was written to solve this equation numerically via explicit finite differencing. All parameters inside parentheses in $\mathrm{k} \nabla \mathrm{T}$ are calculated at node boundaries to ensure conservation of energy. Temperature-dependent Inconel properties were taken from a report by G. Willcutt. ${ }^{5}$

\section{D BENCHMARK AND PARAMETRIC STUDY}

To benchmark the $3 \mathrm{D}$ solution, the conditions of the calculation were altered so that a comparison could be made with the 1D solution. The three calculation conditions that were changed are (1) constant or variable material properties, (2) angular conduction (away from center) through window allowed or not allowed, and (3) wiggler on or off. A parametric study was performed using a $1-\mathrm{mA}, 2 \sigma=3-\mathrm{cm}$ beam, and a coolant temperature of $30^{\circ} \mathrm{C}$ (to be conservative, this is at the high end of the possible window coolant temperature range); the results are presented in Table 1 (theta $=0$ represents the beam centerline).

The top line in Table 1 represents the constant properties 1D solution calculated in the previous section. Here, $\Delta \mathrm{T}$ is calculated as $442.7^{\circ} \mathrm{C}(472.7-30.0)$, which compares very well with the analytical $1 \mathrm{D}$ solution of $445.0^{\circ} \mathrm{C}(126.8+318.2)$. In fact, it turns out that the $\Delta \mathrm{T}$ calculated by the $3 \mathrm{D}$ code is even closer to the $1 \mathrm{D}$ solution because the $3 \mathrm{D}$ code is actually calculating the temperature at an angle of 0.5 degrees (not 0 degrees) because of the finite nodal spacing. As the node spacing is decreased, the calculated temperature approaches the analytical solution. 
TABLE 1

EFFECT OF CALCULATION ASSUMPTIONS ON 3D TEMPERATURE SOLUTION

\begin{tabular}{|c|c|c|c|c|c|c|}
\hline $\begin{array}{c}\text { Constant } \\
\text { materiål } \\
\text { properties? }\end{array}$ & $\begin{array}{c}\text { Angular } \\
\text { conduction } \\
\text { permitted? }\end{array}$ & $\begin{array}{c}\text { Wiggler } \\
\text { on }\end{array}$ & \multicolumn{4}{|c|}{$\begin{array}{c}\text { Steady-state window surface temperature } \\
\text { at a given angle theta }\left({ }^{\circ} \mathbf{C}\right)\end{array}$} \\
\hline yes & no & no & $0^{\circ}$ & $10^{\circ}$ & $20^{\circ}$ & $30^{\circ}$ \\
\hline yes & no & yes & 448.7 & 239.8 & 58.0 & 31.3 \\
\hline yes & yes & no & 460.4 & 236.8 & 60.7 & 31.7 \\
\hline yes & yes & yes & 437.8 & 235.3 & 59.3 & 31.5 \\
\hline no & no & no & 387.9 & 216.1 & 61.9 & 31.9 \\
\hline no & no & yes & 371.4 & 213.7 & 60.0 & 31.3 \\
\hline no & yes & no & 379.0 & 215.0 & 58.7 & 31.5 \\
\hline no & yes & yes & 363.3 & 212.5 & 61.2 & 31.9 \\
\hline
\end{tabular}

The effect of assuming constant properties is demonstrated by comparing the top four rows with the bottom four rows. This effect is very large because the conductivity of Inconel increases by $50 \%$ between 30 and $450^{\circ} \mathrm{C}$. The maximum temperature calculated by the constant properties case would agree more with the variable properties case if the conductivity were calculated at a temperature closer to the average temperature than $30^{\circ} \mathrm{C}$.

The effect of angular conduction reduces the maximum temperature only by $\sim 10^{\circ} \mathrm{C}$. This is because the heat flow path to the coolant (in the radial direction) is considerably shorter and wider than the heat flow path outward through the window.

The wiggler effectively spreads out the beam; thus, the maximum temperatures drop by $\sim 15$ to $25^{\circ} \mathrm{C}$, and the outer temperatures increase slightly. In this analysis, the wiggler radius is assumed to be $5 \mathrm{~mm}$, and the wiggler frequency is $30 \mathrm{~Hz}$ (Ref 2). The maximum periodic temperature swing resulting from the movement of the wiggler is $\sim 1^{\circ} \mathrm{C}$, which occurs at an angle of theta $=7$ degrees on the beam window (1.2 $\mathrm{cm}$ from the centerline).

One other item to note about the above calculations is that steady-state temperatures (disregarding the wiggler oscillations) are reached $\sim 5 \mathrm{~s}$ after the beam is turned on (from cold startup conditions).

\section{FLOW SOLUTION}

The flow rate through the window at the time the test measurements were taken is unknown. For the calculations performed in this report, a flow rate of $3 \mathrm{gpm}$ was assumed. ${ }^{6}$ There is no flow control for the window itself, and because the window usually represents a small percentage of the total XO2 flow system at Area-A, the flow through the window is driven by the pressure drop caused by the remainder of the system. A pressure drop of $60 \mathrm{psi}$ would yield a flow rate of $3 \mathrm{gpm}$, and a pressure drop of 220 psi would yield a flow rate of $\sim 6 \mathrm{gpm}$. Since the time the calculations were performed for this report, we have learned that the measured pressure drop across the window in the materials test configuration is $\sim 129 \mathrm{psi}$ ( $229 \mathrm{psi}$ inlet and $110 \mathrm{psi}$ exit) at $4.33 \mathrm{gpm}$. The calculated pressure drop is $124.8 \mathrm{psi}$, which agrees very well with the measured value.

The flow path through the window is defined by wires between the two hemispheres. The wires form relatively uniform rectangular channels, except at the edges, where the flow transfers to an adjacent channel and reverses direction (however, this region is well outside of the beam). Therefore, the flow path can be approximated as a rectangular channel with dimensions 1 in. $x 1 / 16$ in. For the pressure drop calculation, it is assumed that the flow passes though eight of these flow channels, in addition to 
nine 180-degree bends. For a water flow rate of $3 \mathrm{gpm}$, the flow velocity is $4.7 \mathrm{~m} / \mathrm{s}$ and the Reynolds number is $\sim 16,700$, which is based on the Dittus-Boelter correlation and gives a heat transfer coefficient of $21,700 \mathrm{~W} / \mathrm{m}^{2 \circ} \mathrm{C}$ (at $4.3 \mathrm{gpm} \mathrm{V}=6.7 \mathrm{~m} / \mathrm{s}$ and $\mathrm{h}=29,000 \mathrm{~W} / \mathrm{m}^{2}-{ }^{\circ} \mathrm{C}$ and at $10 \mathrm{gpm}, \mathrm{V}=$ $15.6 \mathrm{~m} / \mathrm{s}$ and $\left.\mathrm{h}=56,600 \mathrm{~W} / \mathrm{m}^{2}-{ }^{\circ} \mathrm{C}\right)$. The above calculations were done by $\mathrm{G}$. Willcutt, assuming a bulk coolant temperature of $25^{\circ} \mathrm{C}$ (Ref. 7). The heat transfer coefficient used for this report is $24,000 \mathrm{~W} / \mathrm{m}^{2 \circ} \mathrm{C}$, which correspond: to $-3.4 \mathrm{gpm}$. At flow rates $>3 \mathrm{gpm}$, the water temperature rise through the window is $<10^{\circ} \mathrm{C}$, so that the change in properties with temperature should not significantly affect $h$. The code offers the ability to calculate the water temperature at each location as a function of inlet temperature and flow rate, but for most solutions, constant water temperature is assumed (not only because the water $\Delta \mathrm{T}$ is small throughout the window, but also because the actual inlet temperature is not accurately known). The test data used in this analysis indicate that the water in the right side of the window (as displayed on the output) was $\sim 17^{\circ} \mathrm{C}$ at the time the data were recorded-the outer right TC reading is $20^{\circ} \mathrm{C}$ at $200 \mu \mathrm{A}$ and $23^{\circ} \mathrm{C}$ at $400 \mu \mathrm{A}$. Past data indicate that the inlet temperature remains $\sim 20^{\circ} \mathrm{C}$ year round. Therefore, $20^{\circ} \mathrm{C}$ is used as the coolant temperature for best estimate calculations; however, to add conservatism, $30^{\circ} \mathrm{C}$ is used as the coolant temperature for predicting maximum window temperatures.

\section{CRITICAL HEAT FLUX}

The wall heat flux is very high $\left(3.0 \mathrm{MW} / \mathrm{m}^{2}\right.$ for a $1 \mathrm{~mA}$ beam with $\left.2 \sigma=3 \mathrm{~cm}\right)$; therefore, the possibility of boiling the coolant must be considered. The pressure drop at the center of the window (where the peak heat flux occurs) will be about halfway between the inlet and outlet pressures, as determined by the total $\mathrm{XO} 2$ flow. It is conservative to assume that the water pressure where the peak heat flux occurs is at least 130 psia (it is probably closer to 160 psia). At 130 psia, the saturation temperature is $175^{\circ} \mathrm{C}$. The peak wall surface temperature at $1-\mathrm{mA}, 3-\mathrm{cm}$ conditions is $155^{\circ} \mathrm{C}$ (for a coolant temperature of $30^{\circ} \mathrm{C}$ ), which would make the water $20^{\circ} \mathrm{C}$ subcooled at the surface and highly subcooled on a bulk basis. Similarly, the corresponding saturation pressure at $156^{\circ} \mathrm{C}$ is 81 psia, which is far below the expected pressure near the center of the window, or in fact anywhere in the window.

The Macbeth-Bowring correlation was used to estimate the critical heat flux. If it is assumed that the water is at $30^{\circ} \mathrm{C}$ and 150 psia and that the heat flux is applied over one entire flow pass, the critical heat flux is $\sim 6.4 \mathrm{MW} / \mathrm{m}^{2}$. Because the maximum heat flux is $3.0 \mathrm{MW} / \mathrm{m}^{2}$, this results in a departurefrom-nucleate-boiling ratio of 2.1. This number is very conservative because the maximum heat flux is actually applied over a very small portion of the flow path, and the assumption of 150 psia is probably conservative as well. However, great care must be taken to prevent the maximum beam power density from becoming significantly larger because the margins are not great.

\section{EFFECT OF COOLANT TEMPERATURE AND FLOW RATE}

All of the analyses done in this study assume a coolant heat transfer coefficient of $24,000 \mathrm{~W} / \mathrm{m}^{2 \circ} \mathrm{C}$ and a water flow rate of $3 \mathrm{gpm}$. Unfortunately, it is not known with much certainty what the flow rate was for the test data. When the flow rate is $3.4 \mathrm{gpm}$, the heat transfer coefficient is such that the film temperature drop accounts for $32 \%$ of the difference between the peak window temperature and the coolant temperature. Therefore, increasing the flow rate can reduce window temperatures only by a maximum of $32 \%$, and in reality much less. A $50 \%$ increase in flow rate to $5.1 \mathrm{gpm}$ would increase the heat transfer coefficient from $24,000 \mathrm{~W} / \mathrm{m}^{2 \circ} \mathrm{C}$ to $33,100 \mathrm{~W} / \mathrm{m}^{2 \circ} \mathrm{C}$. This would reduce window temperatures by $\sim 9 \%$ and reduce the maximum temperature $\sim 34^{\circ} \mathrm{C}$. Increasing the flow rate to $10 \mathrm{gpm}$ (which may not be physically possible given a 300 -psi inlet pressure) only reduces the window temperatures by $20 \%$. Significantly lower flow rates could cause serious increases in window temperature. A flow rate of $1 \mathrm{gpm}$ would cause window temperatures to rise $40 \%$ and create critical heat-flux concerns. 
The effect of coolant temperature is not very important. Lower temperatures generally are desired, but the gain in inlet subcooling margin is offset by a marked increase in coolant viscosity, which leads to a larger pressure drop and a lower saturation temperature.

\section{EXPERIMENTAL DATA}

The data used for this analysis consist of six sets of TC readings obtained on November 30 , 1995, at beam currents ranging from 200 to $700 \mu \mathrm{A}$. The A2 target was in the beamline when these measurements were taken, the A1 target was out, and the wiggler was on. There are 18 thermocouples: 4 in the inner ring (1-in. diam.), 6 in the middle ring (2.5-in. diam.), and 8 in the outer ring (4-in diam.). A photo of the actual window and TCs is found in Appendix A. To determine if the TC readings scale linearly with current, the average temperature of each ring is plotted vs beam current in Fig. 1. The results for the outer two rings scale very well. The inner-ring data have a bit of scatter, but this is not surprising because these locations are most sensitive to small changes in beam diameter and location.

To eliminate some of the uncertainty with individual readings, each of the six test samples was normalized to a current of $700 \mu \mathrm{A}$ (based on an estimated water temperature of $20^{\circ} \mathrm{C}$ ). The average normalized TC readings at each location are shown in Fig. 2. The high TC reading located at $10 o^{\prime}$ 'clock in the middle ring is very suspicious. C. Pillai noted ${ }^{2}$ that one day this TC began giving spurious readings and that the TC has not worked properly since and is therefore not used in these calculations.

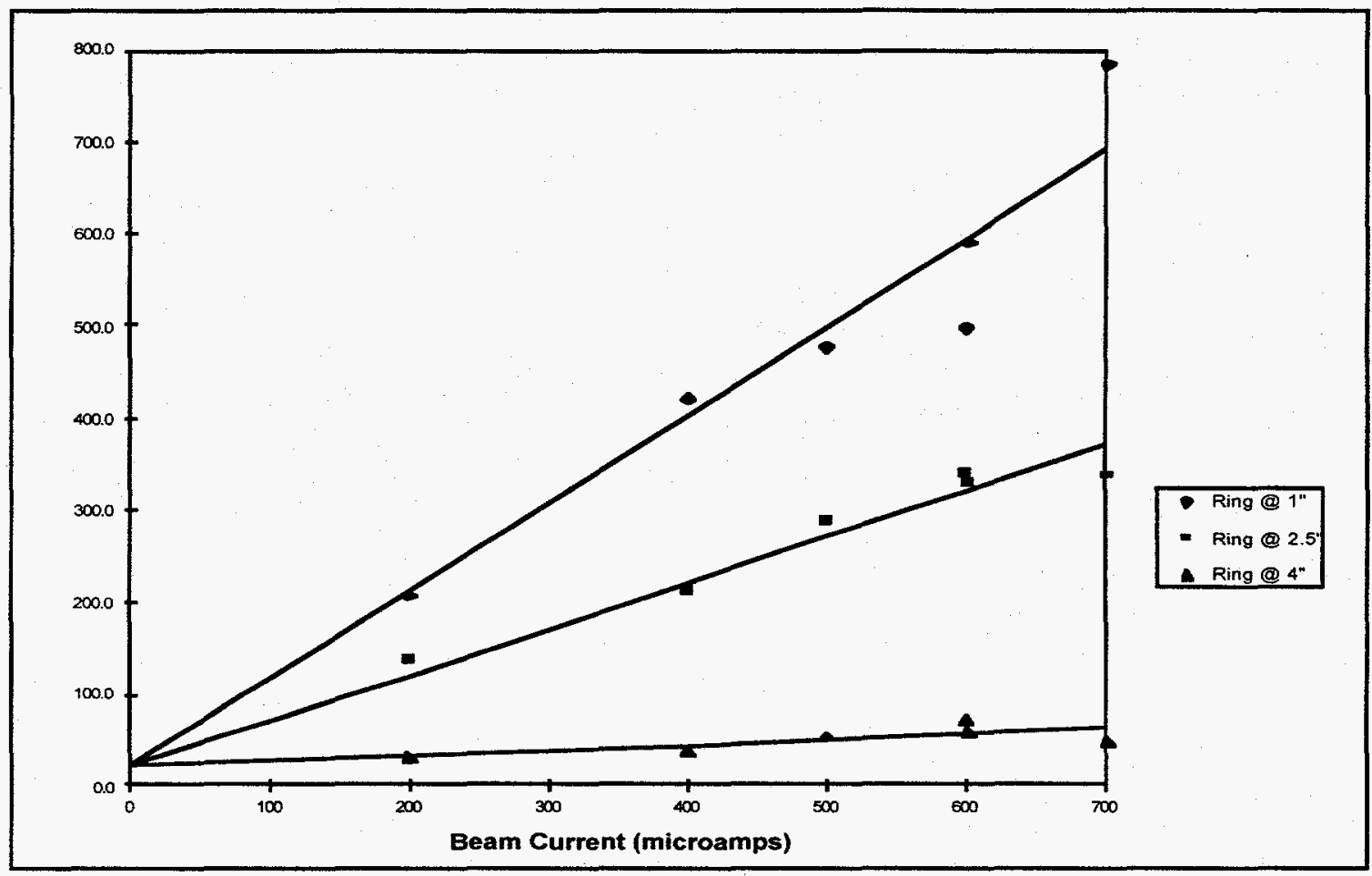

Fig. 1. Average TC readings for each ring as a function of beam current. 


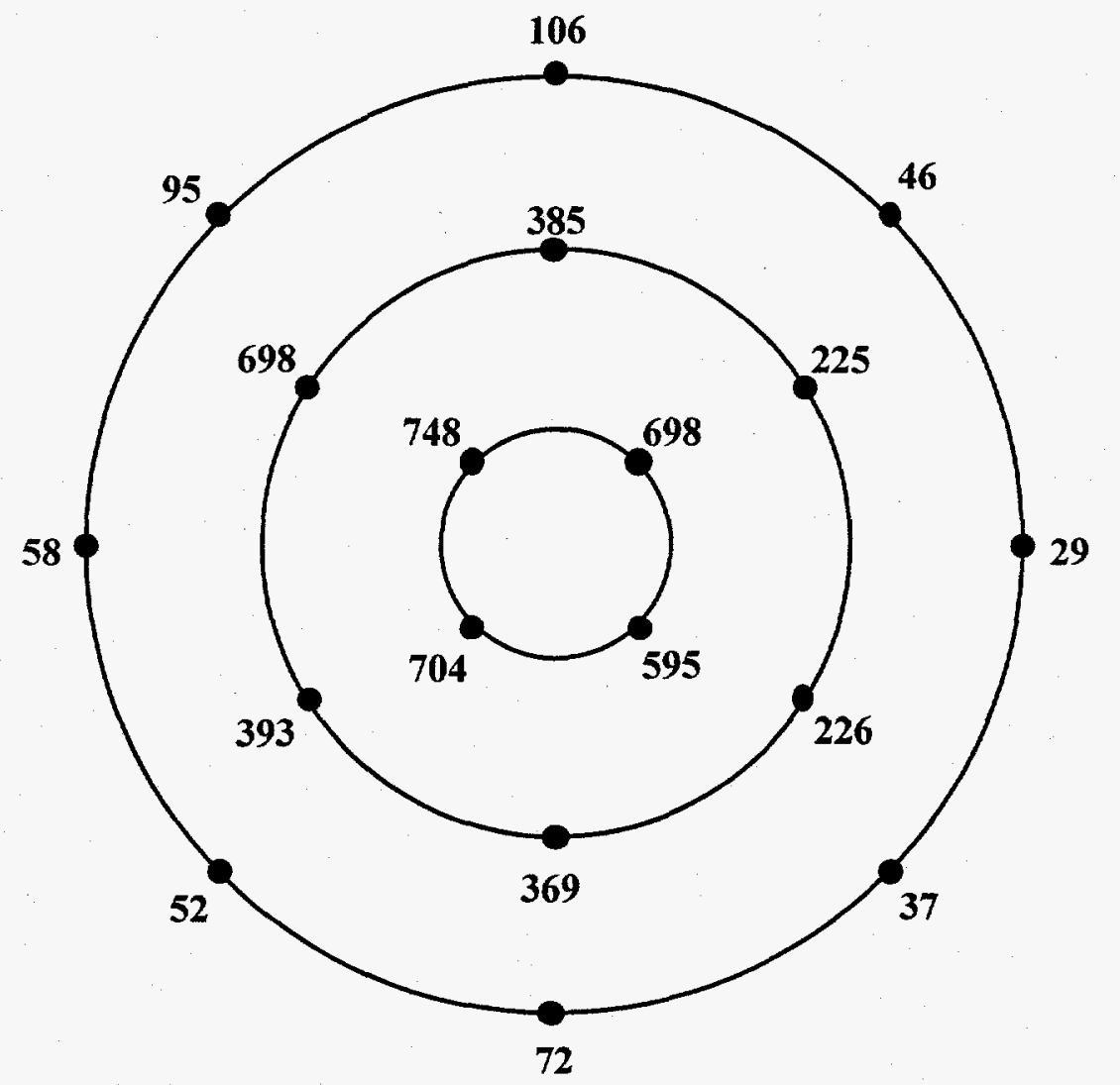

Fig. 2. Normalized readings of window thermocouples $(700 \mu \mathrm{A})$.

\section{BEAM FIT}

To determine how much higher the TC readings are than the actual window temperature, it must first be determined what the beam profile was when the test data were produced. The 3D heat transfer code was used to perform a parametric study that varies $x_{0}, y_{0}, \sigma_{x}, \sigma_{y}$, and $M$. The variable $M$ is a multiplier that is applied to the calculated window temperature $\Delta T\left(T_{\text {win }}-T_{\text {cool }}\right)$, where $T_{\text {win }}$ is the window outer surface temperature and $T_{\text {cool }}$ is the bulk coolant temperature, such that

$$
M=\frac{T_{T C}-T_{\text {cool }}}{T_{\text {win }}-T_{\text {cool }}} .
$$

$M$ determines how much higher the TCs read than the calculated window temperature. The calculated $\Delta \mathrm{T}$ that is used to derive $\mathrm{M}$ is based on the beam current that reaches the window. Upstream targets $\mathrm{Al}$ and $\mathrm{A} 2$ reduce the window current by 8 and 12\%, respectively, if they are in the beam. For each combination of the five variables listed above, the difference between the calculated and measured temperatures is summed at each TC (except the bogus TC, as mentioned earlier). The combination that produces the minimum sum is considered the best beam fit. Certainly, there are several different ways to obtain the best fit, but it is difficult to justify how to best weight the individual TC $\Delta$ ts; therefore, no weighting is used. In one respect, the inner TCs are weighted more than the outer TCs because they are at higher temperatures (larger $\Delta \mathrm{T}$ expected), but this is offset because there are more outer TCs. 
With the $\mathrm{A} 2$ target in, the wiggler on, a coolant temperature of $20^{\circ} \mathrm{C}$, and a flow rate of $3 \mathrm{gpm}$, the best beam fit of the normalized test results given in Fig. 2 (ignoring the 10 o'clock TC in the middle ring) is given by

$\sigma_{\mathrm{x}}=1.80 \mathrm{~cm}, \sigma_{\mathrm{y}}=2.15 \mathrm{~cm}, \mathrm{x}_{0}=-0.30 \mathrm{~cm}, \mathrm{y}_{0}=0.25 \mathrm{~cm}, \mathrm{M}=5.2 \quad$ (calculated beam fit).

In comparison, each individual test data sample gives an approximated beam size. The average of the stated beam profiles from the test data are:

$\sigma_{\mathrm{x}}=1.70 \mathrm{~cm}, \quad \sigma_{\mathrm{y}}=2.00 \mathrm{~cm}, \mathrm{x}_{0}=0.02 \mathrm{~cm}, \mathrm{y}_{0}=-0.10 \mathrm{~cm}$

(test data beam fit).

The values of sigma agree fairly well, but the $x_{0}$ and $y_{0}$ values are off significantly. The values printed on the test data sheets show the beam on the opposite side of the window from the calculated beam fit. Glancing at the data in Fig. 2, it seems intuitive that the beam is to the upper left of center (not the lower right), which supports the calculated beam-fit values of $\mathrm{x}_{0}$ and $\mathrm{y}_{0}$. Using the test data beam profile, the best beam fit corresponds to $M=4.8$, although the error in the test data beam fit is twice as high as the calculated beam fit (using the definition of beam fit as described above). Calculated temperature results for each beam fit are compared with the actual measured values in Table 2.

An $M$ of 5 means that four-fifths of the total $\Delta \mathrm{T}$ that produces the $\mathrm{TC}$ reading is in the TC itself; therefore, if the TC is reading $520^{\circ} \mathrm{C}$, the actual window outer surface temperature is only at $\sim 120^{\circ} \mathrm{C}$ (given a coolant temperature of $20^{\circ} \mathrm{C}$ ). There is much uncertainty in obtaining $\mathrm{M}$, but it is safe to assume that the actual $M$ is at least 4 . The actual value of $M$ should be relatively independent of the beam current and profile.

\section{WINDOW TEMPERATURES AS A FUNCTION OF BEAM CURRENT AND WIDTH}

The ultimate goal of this study was to determine if the window can adequately handle a $1-\mathrm{mA}$ current with a $2 \sigma$ of $3 \mathrm{~cm}$. Table 3 lists the window outer surface temperatures for a variety of beam currents and widths, no wiggler, and a coolant temperature of $30^{\circ} \mathrm{C}$ (as mentioned earlier, $30^{\circ} \mathrm{C}$ is used in this calculation as a conservative upper bound of the coolant temperature).

The maximum window temperature for $1 \mathrm{~mA}$ and $2 \sigma=3 \mathrm{~cm}$ is $\sim 400^{\circ} \mathrm{C}$. These temperatures and the resulting stresses ${ }^{1}$ should not present a significant problem to the window. However, C. Pillai ${ }^{2}$ noted that in the worst possible case, the beam $2 \sigma$ could drop as low as $2 \mathrm{~cm}$. As seen on the bottom line of Table 3, this would result in significantly higher temperatures and possible critical heat flux issues; R. Parker found that the resulting stresses would exceed some material limits.' Therefore, some precautions are required to prevent the window from seeing a $1-\mathrm{mA}, 2-\mathrm{cm}$ beam. If assurance can be given that the beam will never become stronger than $1 \mathrm{~mA}$ and $3 \mathrm{~cm}$, then window temperature diagnostics may not be a requirement. 
TABLE 2

COMPARISON OF CALCULATED AND MEASURED RESULTS OF NORMALIZED TEST

DATA AT $700 \mu$ A AND A COOLANT FLOW OF 3 gpm AT $20^{\circ} \mathrm{C}$

\begin{tabular}{|c|c|c|c|c|}
\hline & $\begin{array}{c}\text { Calculated } \\
\text { window } \\
\text { temperatures } \\
\text { using calculated } \\
\text { beam fit }\end{array}$ & $\begin{array}{c}\text { Actual TC } \\
\text { temperature } \\
\text { measurements }\end{array}$ & $\begin{array}{c}\text { Calculated } T C \\
\text { temperatures } \\
\text { using calculated } \\
\text { beam fit: } \Delta T \\
\text { multiplied by } \\
M=5.2\end{array}$ & $\begin{array}{c}\text { Calculated } T C \\
\text { temperatures } \\
\text { using test data } \\
\text { beam fit: } \Delta T \\
\text { multiplied by } \\
M=4.8\end{array}$ \\
\hline & ${ }^{\circ} \mathrm{C}$ & ${ }^{\circ} \mathrm{C}$ & ${ }^{\circ} \mathrm{C}$ & ${ }^{\circ} \mathrm{C}$ \\
\hline \multirow[t]{4}{*}{ Inner TC Ring } & 144 & 698 & 665 & 692 \\
\hline & 163 & 748 & 762 & 685 \\
\hline & 151 & 704 & 703 & 711 \\
\hline & 134 & 595 & 614 & 718 \\
\hline \multirow[t]{2}{*}{ Middle TC Ring } & 61 & 225 & 231 & 237 \\
\hline & 89 & 385 & 378 & 285 \\
\hline \multirow[t]{4}{*}{ (bogus TC) } & 82 & (698) & 342 & 230 \\
\hline & 73 & 393 & 297 & 245 \\
\hline & 71 & 369 & 286 & 323 \\
\hline & 55 & 226 & 201 & 252 \\
\hline \multirow[t]{8}{*}{ Outer TC Ring } & 24 & 29 & 41 & 44 \\
\hline & 28 & 46 & 63 & 54 \\
\hline & 38 & 106 & 114 & 69 \\
\hline & 35 & 95 & 98 & 52 \\
\hline & 29 & 58 & 68 & 43 \\
\hline & 31 & 52 & 75 & 58 \\
\hline & 31 & 72 & 78 & 81 \\
\hline & 26 & 37 & 50 & 60 \\
\hline
\end{tabular}

\section{PREDICTED WINDOW AND THERMOCOUPLE TEMPERATURES FOR A 1-mA BEAM}

Table 4 shows the expected window temperature and TC readings at several locations given a $1-\mathrm{mA}$, $3-\mathrm{cm}$ beam. Expected TC readings are given for multiplier values $\mathrm{M}$ of both 4.5 and 5.5 because there is a lot of uncertainty in this value. The wiggler is off, and the coolant temperature is assumed to be $30^{\circ} \mathrm{C}$ at all locations. As mentioned earlier, the heat transfer coefficient is based on $3.4 \mathrm{gpm}$, but the flow rate was not well quantified in the past. This could affect the numbers in Table 4. For example, if the present-day flow is $5.1 \mathrm{gpm}$ but the flow was $3.4 \mathrm{gpm}$ when the test data were obtained, then all numbers on the chart should be reduced by $9 \%$. If the present day flow is $5.1 \mathrm{gpm}$ and the flow was $5.1 \mathrm{gpm}$ when the test data were obtained, then the predicted window temperatures should drop by $9 \%$, but the predicted TC temperatures should remain about the same (because the data fit multiplication factor would be higher). In addition, the uncertainty in these numbers (in addition to the multiplication factor) is extremely large, perhaps as high as $25 \%$.

The most important thing to note about the data in Table 4 is that the inner-ring TC readings are extremely high. The TCs are probably not designed to handle these temperatures, and they will most likely fail. The middle-ring TC readings are highly dependent on beam width and decrease significantly as the beam width gets tighter. The outer-ring readings at tight-beam widths are bound tightly to the coolant temperature; thus, they are hard to predict unless the actual coolant temperatures are known. If the inner TCs fail, the only way the other TCs could be used as a safety trip would be to set a lower temperature limit on the middle-ring TCs provided that the beam current 
TABLE 3

EFFECT OF BEAM CURRENT AND WIDTH ON WINDOW TEMPERATURES

\begin{tabular}{|c|c|c|c|c|c|}
\hline $\begin{array}{c}\text { Current } \\
\text { mA }\end{array}$ & $\begin{array}{c}2 \sigma \\
\text { cm }\end{array}$ & \multicolumn{4}{|c|}{$\begin{array}{c}\text { Steady-state Window Surface Temperature } \\
\text { at a Givea Angle Theta }\left({ }^{\circ} \mathbf{C}\right)\end{array}$} \\
\hline & & 0 & 10 & 20 & 30 \\
\hline 0.7 & 4.0 & 185.1 & 136.0 & 66.3 & 36.8 \\
\hline 1.0 & 4.0 & 243.8 & 177.4 & 81.4 & 39.7 \\
\hline 0.7 & 3.0 & 286.4 & 163.7 & 50.2 & 31.0 \\
\hline 1.0 & 3.0 & 379.0 & 215.0 & 58.7 & 31.5 \\
\hline 0.7 & 2.0 & 524.2 & 154.3 & 31.9 & 30.0 \\
\hline 1.0 & 2.0 & 687.6 & 202.5 & 32.7 & 30.0 \\
\hline
\end{tabular}

TABLE 4

PREDICTED WINDOW AND THERMOCOUPLE TEMPERATURES FOR A 1-mA BEAM

\begin{tabular}{|c|c|c|c|c|c|}
\hline & \multirow{2}{*}{$\begin{array}{c}\text { Beam } \\
\text { width } \\
2 \sigma(\mathrm{cm})\end{array}$} & \multicolumn{4}{|c|}{ Steady-state window surface temperature $\left({ }^{\circ} \mathrm{C}\right)$} \\
\hline & & Centerline & $\begin{array}{c}\text { Inner TC } \\
\text { ring ( } 1 \text { in.) }\end{array}$ & \begin{tabular}{|c|} 
Middle TC \\
ring (2.5 in.
\end{tabular} & $\begin{array}{l}\text { Outer TC } \\
\text { ring (4 in.) }\end{array}$ \\
\hline Predicted window temperature & 4.0 & 244 & 209 & 102 & 44 \\
\hline Predicted $\mathrm{TC}$ reading, $\mathrm{M}=4.5$ & 4.0 & & 840 & 353 & 92 \\
\hline Predicted TC reading, $\mathrm{M}=5.5$ & 4.0 & & 1020 & 425 & 106 \\
\hline Predicted window temperature & 3.0 & 379 & 291 & 82 & 33 \\
\hline Predicted TC reading, $M=4.5$ & 3.0 & & 1202 & 265 & 42 \\
\hline Predicted TC reading, $\mathrm{M}=5.5$ & 3.0 & & 1462 & 318 & 45 \\
\hline Predicted window temperature & 2.0 & 688 & 391 & 40 & 30 \\
\hline Predicted TC reading, $M=4.5$ & 2.0 & & 1655 & 77 & 30 \\
\hline Predicted TC reading, $\mathrm{M}=5.5$ & 2.0 & & 2017 & 87 & 30 \\
\hline
\end{tabular}

was $1 \mathrm{~mA}$. This would be very difficult to implement reliably because of beam power and position variations.

\section{THERMOCOUPLE MODEL}

A detailed heat transfer model of the TCs (actually TC units as defined in the Introduction) was generated in parallel with the window heat transfer model. In the TC unit, an Inconel tab wraps over the top of a stainless-steel sheath. The tab is spot welded to the sheath and to the window. Inside the sheath there is a layer of $\mathrm{MgO}$ insulation that surrounds the $\mathrm{NiCr}$ and $\mathrm{NiAl} \mathrm{TC}$ wires, except at the tip. The tab, sheath, and TC wires are each 10 mil thick, the tab is a $1 / 2$-in. square, and the sheath's outer diameter is $62 \mathrm{mil}$. The TC is discretized into 33 nodes, as shown in Fig. 3 . A FORTRAN code was written to calculate the heat transfer between all nodes and the window. A contact resistance or gap conductance can be specified at any surface, or solid conduction can be assumed. The window is assumed to be a constant temperature boundary condition. Radiation and natural convection to the ambient environment are ignored; preliminary calculations showed both heat transfer mechanisms to be negligible (unless temperatures are extremely high). Constant 


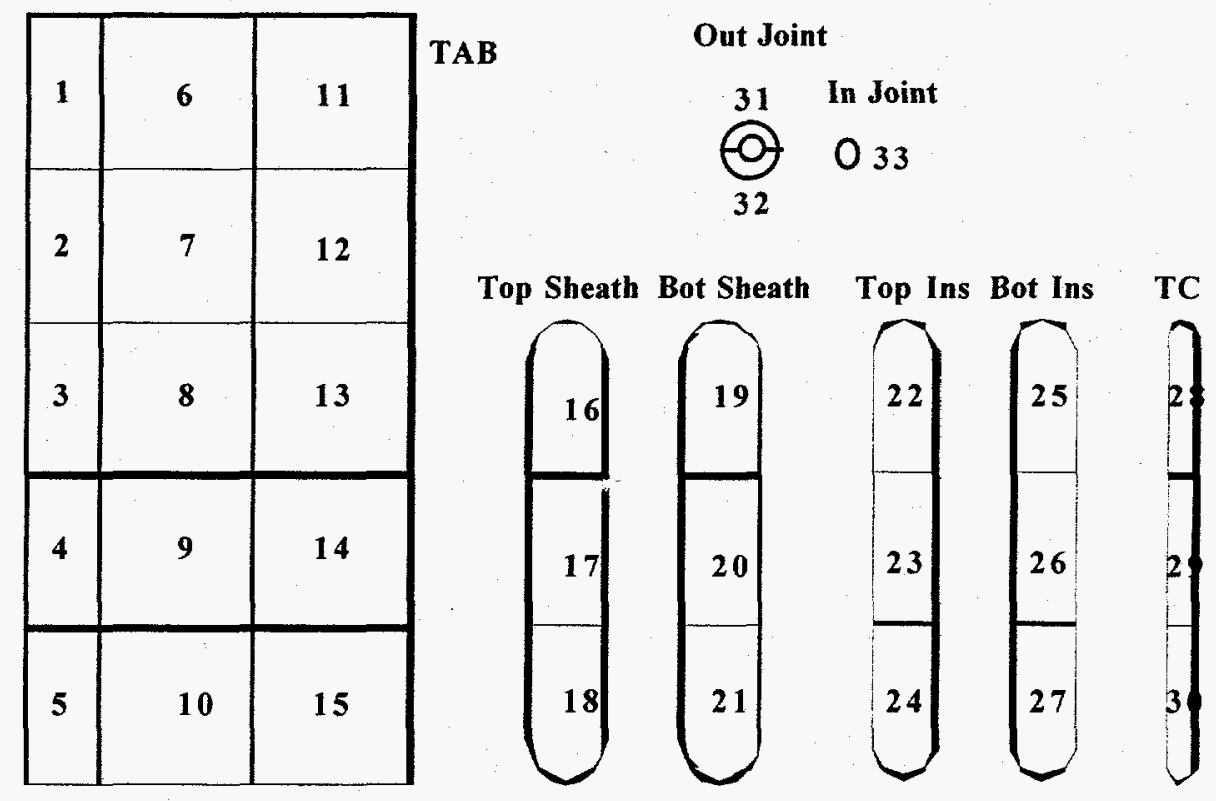

Fig. 3. Thermocouple discretization.

temperature properties are used at $700 \mathrm{~K}$. The power density used is $1260 \mathrm{~W} / \mathrm{cm}^{3}$ (same as nickel for a $1-\mathrm{mA}, 3-\mathrm{cm}$ beam) for each of the metals, and $129 \mathrm{~W} / \mathrm{cm}^{3}$ for the $\mathrm{MgO}$ (Ref. 4).

There is really no way to predict what the effective contact resistances are between each surface. Therefore, a parametric study was performed that varies the conductivity between the following three key surfaces: (1) sheath to window, (2) tab to window, and (3) sheath to tab. For each surface, the conductivity is varied from solid metal contact (defined as 1.0 in Table 5) to perfect insulation (defined as 0.0 in Table 5). A value of 0.01 in Table 5 would mean that the effective conductivity is $1 \%$ that of solid metal contact (no contact resistance) over the entire surface area. For the sheathto-window conductivity, the surface area is based on a length equal to the diameter of the sheath. In this case, a value of 1.0 might be representative of a solid braze completely filling the gap between the sheath and window. Table 5 lists the $\Delta \mathrm{T}\left(\mathrm{T}_{\mathrm{TC}}-\mathrm{T}_{\text {win }}\right)$ within the $\mathrm{TC}$ unit for a wide range of conductivities between the surfaces. $\Delta \mathrm{T}$ is calculated based on the TC being in the center of a $1-\mathrm{mA}$, $3-\mathrm{cm}$ beam.

The data in Table 5 show that even if there is perfect contact between all surfaces, the $\Delta \mathrm{T}$ is still $>200^{\circ} \mathrm{C}$. Once again, the $\Delta \mathrm{Ts}$ listed above are for a TC directly in the center of a $1-\mathrm{mA}$, 3-cm beam. The actual TCs are offset from the center of the beam so their $\Delta T$ s would be lower. The inner row is at a 0.5 -in. radius from the centerline, which would have $70 \%$ of the peak power density; thus, $70 \%$ of the $\Delta \mathrm{T}$ listed in the table above (the middle row is only $10 \%$ and the outer row is only $3 \%$ ).

For the test data, the results were normalized to $0.7 \mathrm{~mA}$ for a beam with a width of $2 \sigma \sim 3.9 \mathrm{~cm}$. This would produce about one-third of the power density of the centerline $1-\mathrm{mA}, 3-\mathrm{cm}$ condition. From Table 2 it can be calculated that the inner-ring TCs are reading $\sim 550^{\circ} \mathrm{C}$ higher than the predicted window temperature. This would correspond to a $\Delta \mathrm{T}$ of $\sim 1150^{\circ} \mathrm{C}$ in Table 5 because the power density is three times higher, which means that the sheath-to-window conductivity is probably 
somewhere between 0.01 and 0.001 times that of solid metal contact. Recall that the sheath-towindow conductivity is based on a surface area over the entire diameter of the sheath. Even in the best case, the sheath will contact the window over only a few angular degrees of surface area, which would make the multiplication factor close to 0.01 , even if the contact were solid. There is a good chance that the sheath-to-window contact is very poor, and thus it is possible that the multiplication factor is as low as 0.001 . Multiplication factors of 0.01 and 0.001 correspond to gap conductivities of $1200 \mathrm{~W} / \mathrm{m}^{2}-{ }^{\circ} \mathrm{C}$ and $120 \mathrm{~W} / \mathrm{m}^{2}-{ }^{\circ} \mathrm{C}$, respectively. The conductivity of an air gap can be estimated by dividing the conductivity of air $\left(0.034 \mathrm{~W} / \mathrm{m}-{ }^{\circ} \mathrm{C}\right.$ at $\left.130^{\circ} \mathrm{C}\right)$ by the average distance from the sheath to the window $\left(0.214 \mathrm{R}_{\text {sheath }}=0.00017 \mathrm{~m}\right.$, assuming that the sheath is flush with the window at its closest point). This gives a gap conductivity of $200 \mathrm{~W} / \mathrm{m}^{2}-{ }^{\circ} \mathrm{C}$, which falls at the low end of the predicted range of 0.01 to 0.001 .

The sheath-to-tab and tab-to-window conductivities might be expected to fall between 0.1 and 0.01 because these surfaces are fairly well attached with spot welds. These values, in cornection with the values of 0.01 and 0.001 for the sheath to window, map out a region in Table 5 that yields $\Delta \mathrm{Ts}$ consistent with the value of $1150^{\circ} \mathrm{C}$ predicted by the window heat transfer model and test data. The bottom line of this analysis is that the TC heat transfer model, the window heat transfer model, and the test data are all consistent with each other.

TABLE 5

THERMOCOUPLE $\Delta \mathrm{T}\left(\mathrm{T}_{\mathrm{TC}}-\mathrm{T}_{\mathrm{WIN}} \mathrm{IN}^{\circ} \mathrm{C}\right)$ FOR VARIOUS SURFACE CONDUCTIVITIES AT THE CENTER OF A 1-mA/3-cm BEAM.

Sheath to tab conductivity $=1.0$ (solid metal contact, i.e., no gap)

\begin{tabular}{|c|c|c|c|c|c|}
\hline & \multicolumn{5}{|c|}{ sheath window } \\
\hline tab window & 1.000 & 0.100 & 0.010 & 0.001 & 0.000 \\
\hline 1.000 & $\mathbf{2 5 2}$ & $\mathbf{3 3 6}$ & $\mathbf{7 0 0}$ & $\mathbf{1 0 1 6}$ & $\mathbf{1 0 8 2}$ \\
\hline 0.100 & $\mathbf{2 5 9}$ & $\mathbf{3 4 5}$ & $\mathbf{7 2 7}$ & $\mathbf{1 0 6 6}$ & $\mathbf{1 1 3 8}$ \\
\hline 0.010 & $\mathbf{3 0 9}$ & $\mathbf{4 2 0}$ & $\mathbf{9 4 8}$ & $\mathbf{1 4 8 0}$ & $\mathbf{1 6 0 2}$ \\
\hline 0.001 & $\mathbf{5 5 7}$ & $\mathbf{7 9 7}$ & $\mathbf{2 2 3 5}$ & $>\mathbf{3 0 0 0}$ & $>\mathbf{3 0 0 0}$ \\
\hline 0.000 & $\mathbf{9 5 5}$ & $\mathbf{1 4 3 8}$ & $\mathbf{3 0 0 0}$ & $>\mathbf{3 0 0 0}$ & $\mathbf{3 0 0 0}$ \\
\hline
\end{tabular}

Sheath to tab conductivity $=0.01(1 \%$ of solid metal contact $)$

\begin{tabular}{|c|c|c|c|c|c|}
\hline & \multicolumn{5}{|c|}{ sheath window } \\
\hline tab window & 1.000 & 0.100 & 0.010 & 0.001 & 0.000 \\
\hline 1.000 & $\mathbf{2 4 4}$ & $\mathbf{3 4 2}$ & $\mathbf{9 5 0}$ & $\mathbf{2 0 1 9}$ & $\mathbf{2 3 9 1}$ \\
\hline 0.100 & $\mathbf{2 4 7}$ & $\mathbf{3 4 6}$ & $\mathbf{9 6 5}$ & $\mathbf{2 0 6 3}$ & $\mathbf{2 4 4 7}$ \\
\hline 0.010 & $\mathbf{2 6 9}$ & $\mathbf{3 8 0}$ & $\mathbf{1 0 9 1}$ & $\mathbf{2 4 2 8}$ & $\mathbf{2 9 2 0}$ \\
\hline 0.001 & $\mathbf{4 1 4}$ & $\mathbf{6 0 3}$ & $\mathbf{1 9 4 6}$ & $>\mathbf{3 0 0 0}$ & $>\mathbf{3 0 0 0}$ \\
\hline 0.000 & $\mathbf{8 5 3}$ & $\mathbf{1 2 9 9}$ & $>\mathbf{3 0 0 0}$ & $>\mathbf{3 0 0 0}$ & $>\mathbf{3 0 0 0}$ \\
\hline
\end{tabular}

Sheath to tab conductivity $=0$ (i.e., tab not present)

\begin{tabular}{|c|c|c|c|c|c|}
\hline & \multicolumn{5}{|c|}{ sheath window } \\
\hline tab window & 1.000 & 0.100 & 0.010 & 0.001 & 0.000 \\
\hline 1.000 & $\mathbf{2 3 8}$ & $\mathbf{3 4 4}$ & $\mathbf{1 2 9 2}$ & $>\mathbf{3 0 0 0}$ & $>\mathbf{3 0 0 0}$ \\
\hline 0.100 & $\mathbf{2 3 8}$ & $\mathbf{3 4 4}$ & $\mathbf{1 2 9 2}$ & $>\mathbf{3 0 0 0}$ & $>\mathbf{3 0 0 0}$ \\
\hline 0.010 & $\mathbf{2 3 8}$ & $\mathbf{3 4 4}$ & $\mathbf{1 2 9 2}$ & $>\mathbf{3 0 0 0}$ & $>\mathbf{3 0 0 0}$ \\
\hline 0.001 & $\mathbf{2 3 8}$ & $\mathbf{3 4 4}$ & $\mathbf{1 2 9 2}$ & $>\mathbf{3 0 0 0}$ & $>\mathbf{3 0 0 0}$ \\
\hline 0.000 & $\mathbf{2 3 8}$ & $\mathbf{3 4 4}$ & $\mathbf{1 2 9 2}$ & $>\mathbf{3 0 0 0}$ & $>\mathbf{3 0 0 0}$ \\
\hline
\end{tabular}


One factor that could impact TC readings might be changes in the electrical properties of the TC metals while in the presence of the beam. The possibility of this effect was not investigated in this study.

\section{TEMPERATURE MEASUREMENT RECOMMENDATIONS}

Table 5 indicates how difficult it is to obtain reliable TC readings in the direct path of the beam. Unless the TCs are very well attached, the $\triangle \mathrm{T}$ within the TCs will dominate the total $\mathrm{TC}$ reading. Even if the tab is well connected to the window, considerable $\Delta T$ is generated in transferring the heat through the tab to the window. The best heat transfer scenario would be if the sheath were well connected (possibly brazed along the entire length) to the window and the tab did not exist at all. However, even in this case, the $\Delta \mathrm{T}$ within the $\mathrm{TC}$ is very high because of the distance the heat has to travel through the insulation and/or sheath. If a new window is used in the future, it is recommended that smaller-diameter TC units be made that are well attached directly to the window. If at all possible, the best way to obtain window temperatures might be to use some type of optical technique.

\section{BEAM-WIDTH DISCREPANCY}

While analyzing the beam profile data, a major discrepancy was found between the beam width printed on the harp-wire output and the beam width printed on the window TC output. One specific case analyzed was a 485- $\mu \mathrm{A}$ beam run at 17:08:36 on August 30, 1996. The harp output gives a beam width $(2 \sigma)$ of $3.0 \mathrm{~cm}$, whereas the TC output gives a beam width of $3.8 \mathrm{~cm}$. Two steps were taken in an attempt to resolve this discrepancy. First, the $3 \mathrm{D}$ window model was applied to the actual TC readings to obtain a beam fit. Second, a hand-drawn beam fit was applied to the actual harp-wire printout. The beam widths predicted by each method are listed below in Table 6 .

The data in Table 6 indicate that the printed beam width in the harp output is probably incorrect. The data from the harp wire itself are not in question, rather it is the fitting technique applied to the data that is questionable. Another indication that the beam width is wider than printed is that a $3-\mathrm{cm}$ beam would cause very little heatup in the outer-window TCs; they would be running (on average) $\sim 10^{\circ} \mathrm{C}$ above the coolant temperature. The average outer-row $\mathrm{TC}$ reading is $60^{\circ} \mathrm{C}$, whereas the coolant temperature is expected to be only $\sim 20$ to $30^{\circ} \mathrm{C}$. These readings could be explained by a large beam halo; however, C. Pillai ${ }^{2}$ stated that the halo is usually 1 to $2 \%$ of the total beam current. Also, this fraction is spread over a large area, and thus, the resulting power density should be $<1 \%$ of the peak power density. The outer-row TCs indicate that the outer row is seeing $\sim 3 \%$ of the peak

TABLE 6

BEAM-WIDTH PREDICTIONS OF VARIOUS METHODS

\begin{tabular}{|l|c|c|}
\hline \multicolumn{1}{|c|}{ Fit } & $\mathbf{2} \sigma_{\mathrm{x}}$ & $\mathbf{2} \sigma_{\mathrm{y}}$ \\
\hline Harp printout & 3.0 & 3.0 \\
\hline Window TC printout & 3.8 & 3.9 \\
\hline 3D window model beam fit & 3.6 & 3.9 \\
\hline Hand fit on harp output & 3.7 & 3.6 \\
\hline
\end{tabular}


power density. Another possibility is that the heat is conducted outward through the windows to the outer rows. This spreading is taken into account in the 3D models, and the effect of outward conduction is very small. The conduction path to the water is very short $(\sim 2 \mathrm{~mm})$, whereas the heat would have to travel on the order of centimeters through a thin cross-sectional area to be redistributed significantly. The possibility that a large oxide layer may be causing the heat to spread outward was also considered. A 30-nil copper oxide layer doubles the effect of outward conduction, but it is still a relatively minor effect. The only other possibilities are that the outer TCs are not as well attached as the inner ones or that they are closer to the beam centerline than the quoted 2 in.; however, none of these possibilities (other than a wider beam) would explain why the inner TC readings do not correspond to a $3-\mathrm{cm}$ beam.

This issue is very significant because the peak power density for a $3.8-\mathrm{cm}$ Gaussian beam is $40 \%$ less than for a $3.0-\mathrm{cm}$ Gaussian beam. If the beam width printed on the harp-wire output is being used as the officisl beam width and the conclusion above is correct, then the dose to peak samples in the beam could be 30 to $40 \%$ lower than expected, while the dose to peripheral samples could be significantly more than expected.

\section{POSSIBLE OXIDE LAYER BUILDUP WINDOW COOLANT PASSAGE}

Water-cooled Inconel surfaces have been known to experience considerable oxide buildup at the Los Alamos Neutron Scattering Center. R. Brown ${ }^{6}$ and R. Werbeck ${ }^{8}$ noted that certain components have seen up to $1 / 32$ in. of copper-oxide buildup. If such a layer were to build up inside the window, the window could see significantly higher temperatures and thermal stresses, although the high velocity through the window ( $>5 \mathrm{~m} / \mathrm{s})$ may make it less likely to develop an extremely thick oxide layer than other components.

The effect of a copper-oxide layer on heat transfer was studied by adding this layer to the 3D window model. Two possibilities were studied: (1) a uniform oxide layer over the entire window and (2) an oxide thickness that is a function of beam intensity (i.e., the oxide thickness is greatest at the beam centerline and approximately zero at the window edges). The value used for the conductivity of the oxide is $10 \mathrm{~W} / \mathrm{m}-{ }^{\circ} \mathrm{C}$, which was obtained from the CRC Handbook of Chemistry and Physics. ${ }^{\circ}$ There is much uncertainty in this number because the conductivity of an oxide can vary greatly, depending on how it is formed. For a $1-\mathrm{mA}, 3-\mathrm{cm}$ beam, the maximum window temperature increases $\sim 5^{\circ} \mathrm{C} / \mathrm{mil}$ of uniform oxide layer. If the layer thickness is beam-intensity dependent, then the increase in the maximum temperature is slightly less because of heat conduction outward from the centerline. A $1 / 32$-in. oxide layer would cause $>150^{\circ} \mathrm{C}$ maximum temperature increase, which would put significantly more thermal stress on the window and possibly put the window in jeopardy.

The current Area-A window was installed in the summer of 1995. In an attempt to infer if a large oxide layer has built up on the window, TC data have been evaluated over the window's life. From the beginning it was clear that this would be difficult because of the large uncertainty in the TC readings; however, it seemed logical to proceed with the study because the heat transfer model already had been developed. More than 30 sets of TC data were obtained from T. Newlin of Los Alamos Group L-7 that range in date from August 1995-April 1997. In most cases, the data are in batches of three or four printouts over a short period ( 2 days to 1 week); these results were added together in an attempt to reduce the error. The beam fit obtained for each of these batches is listed in Table 7.

The total window beam time is an approximation based on the beam runs of August 1-November 30, 1995 , and September 1-November 3, 1996. The A1 and A2 targets reduce window current by $\sim 8$ and $12 \%$, respectively. The estimated beam width is based on a Gaussian fit of TC readings, although the $\mathrm{A} 1$ and $\mathrm{A} 2$ targets undoubtedly change the profile of the beam. 
TABLE 7

TC MULTIPLIER VS WINDOW EXPOSURE

\begin{tabular}{|l|c|c|c|c|c|c|c|}
\hline \multicolumn{1}{|c|}{ Runs (by date) } & $\begin{array}{c}\text { Total } \\
\text { window } \\
\text { beam time } \\
\text { (weeks) }\end{array}$ & $\begin{array}{c}\text { Wiggler } \\
\text { status }\end{array}$ & $\begin{array}{c}\text { A1 } \\
\text { target }\end{array}$ & $\begin{array}{c}\text { A2 } \\
\text { target }\end{array}$ & $\begin{array}{c}\text { Current to } \\
\text { window } \\
(\mu \mathbf{A})\end{array}$ & $\begin{array}{c}\text { Estimated } \\
\text { beam width } \\
(\mathrm{cm})\end{array}$ & $\begin{array}{c}\text { TC } \\
\text { multiplier }\end{array}$ \\
\hline Aug. 21-29, 1995 & 3 & on & in & in & 803 & 5.2 & 5.4 \\
\hline Sept. 7-8, 1995 & 5 & on & in & in & 801 & 5.2 & 5.2 \\
\hline Nov. 7-8, 1995 & 14 & on & in & in & 807 & 5.2 & 5.3 \\
\hline Nov. 24-26, 1995 & 16 & on & out & in & 794 & 4.2 & 5.4 \\
\hline Aug. 30, 1996 & 17 & off & out & out & 485 & 3.8 & 5.7 \\
\hline Apr. 9-10, 1997 & 30 & off & out & out & 1003 & 3.3 & 3.0 \\
\hline Apr. 16-18, 1997 & 31 & off & out & out & 1002 & 3.8 & 3.4 \\
\hline
\end{tabular}

The TC multiplier is the parameter $M$ that was described earlier in the report. This represents how much higher the TCs are reading than the calculated window temperature. If a large oxide layer were gradually building up, the TC multiplier would gradually increase with exposure provided that the calculated window temperature assumed no oxide. The TC multiplier remains relatively constant all the way through the first run cycle, indicating that there is no buildup. This is by no means conclusive. Analysis shows that a $1 / 32$-in. oxide layer would cause $M$ to increase only by $\sim 10 \%$, which would be barely distinguishable given the uncertainty in the data. A layer $<10$ mil thick would be extremely difficult to "detect." The fact that a substantial oxide layer has physically been seen on Inconel structures in the past carries significantly more weight than does this analysis.

A possibly more important point of Table 7 is the dramatic drop in M for the April 1997 data. The readings for the TCs are much lower than expected. The lower readings possibly could be explained by a leak that was diagnosed in the cooling system. If water were sprayed onto the TC side of the window, then the readings for the TCs could be significantly lower than expected. Also, it is obvious from the sporadic readings of individual TCs that many (maybe all) of the TCs are no longer functioning well; this could also explain the unexpected readings. However, the drop in $M$ is so large that it warrants additional investigation to ensure that the current is as high as expected.

\section{CONCLUSIONS}

From these analyses we can draw the following conclusions.

- The beam window should be able to handle the APT materials test beam (current $=1 \mathrm{~mA}$, $2 \sigma=3 \mathrm{~cm}$ ) without consequence, but the margins to failure are small. The maximum temperature is expected to be $\sim 400^{\circ} \mathrm{C}$, the maximum stresses are $\sim 70 \%$ of yield, and the coolant margin to boiling is adequate, but small.

- The beam width should not be allowed to go below $2 \sigma=3 \mathrm{~cm}$. The window may not survive the worst-case beam profile of $1 \mathrm{~mA}, 2 \sigma=2 \mathrm{~cm}$. If exposure is prolonged at this level, then the window will most likely not survive.

- The temperature limit on the TCs must be raised above the current value of $900^{\circ} \mathrm{C}$. Expected readings in the inner ring of TCs are between 1200 and $1450^{\circ} \mathrm{C}$ and possibly higher at specific locations if the beam is off-center.

- There is a good chance that the TCs in the inner ring will not survive the high temperatures they will experience, leaving only the middle and outer rings for beam diagnostics. 
- It will be very difficult to use the middle and outer TCs as a safety trip mechanism. If the beam gets tighter, causing maximum temperatures to increase, the readings of these TCs will go down. Thus, a dual-logic system would be required that tripped on a minimum temperature, provided that the beam current was sufficiently high. This would be very difficult to implement because of beam power and position fluctuations.

- If reliable temperature readings are desired near the center of the beam, new TCs should be designed that are smaller and more efficiently attached to the window (possibly brazed along the entire length), or optical measurement techniques should be used.

- In the past, the actual Area-A beam width was 20 to $25 \%$ greater than the harp-wire printout suggested. The data from the harp wire itself were not in question; rather, it was the fitting technique applied to the data that was dubious. This is a very important issue because the dose to peak samples in the beam zould be 30 to $40 \%$ lower than expected, whereas the dose to peripheral samples could be significantly higher than expected. As of April 1997, this conclusion has been acknowledged and the problem addressed.

- A large (>10 mil) copper-oxide layer on the window coolant passage would significantly affect heat transfer. A $1 / 32$-in. oxide layer would cause a $>150^{\circ} \mathrm{C}$ maximum temperature increase for a $1-\mathrm{mA}, 3-\mathrm{cm}$ beam, which would put significantly more thermal stress on the window and possibly put the window in jeopardy. A crude analysis of window TC readings over the life of the window showed no evidence of a large oxide buildup, but the study is by no means conclusive. The fact that a substantial oxide layer has been seen on Inconel structures in the past carries significantly more weight than does this analysis.

- The TC readings of April 1997 are much lower than expected. The lower readings possibly could be explained by a leak that was diagnosed in the cooling system. Another contributing factor could be that almost all of the TCs no longer are functioning properly. Whatever the reason, the readings are so low that this issue should be investigated to ensure that the current is as high as advertised.

\section{ACKNOWLEDGMENT}

The author would like to thank everyone who contributed to this report, especially R. Brown, T. Newlin, C. Pillai, W. Sommer, R. Werbeck, and G. Willcutt.

\section{REFERENCES}

1. R. Parker, Los Alamos National Laboratory, personal communication, August 1996.

2. C. Pillai, Los Alamos National Laboratory, personal communication, June 1996.

3. T. Newlin, Los Alamos National Laboratory, personal communication, April 1997.

4. P. Ferguson, Los Alamos National Laboratory, personal communication, July 1996.

5. G. Willcutt, "Thermal Properties for APT Structural Materials-Rev. 2," Los Alamos National Laboratory memorandum N-12-93-271 (May 19, 1993).

6. R. Brown, Los Alamos National Laboratory, personal communication, March 1996.

7. G. Willcutt, Los Alamos National Laboratory, personal communication, February 1997.

8. R. Werbeck, Los Alamos National Laboratory personal communication, March 1997.

9. D. R. Lide, CRC Handbook of Chemistry and Physics, 71st Ed. (CRC Press, 1990) 
Appendix A. Photo of Area A Window and Thermocouples

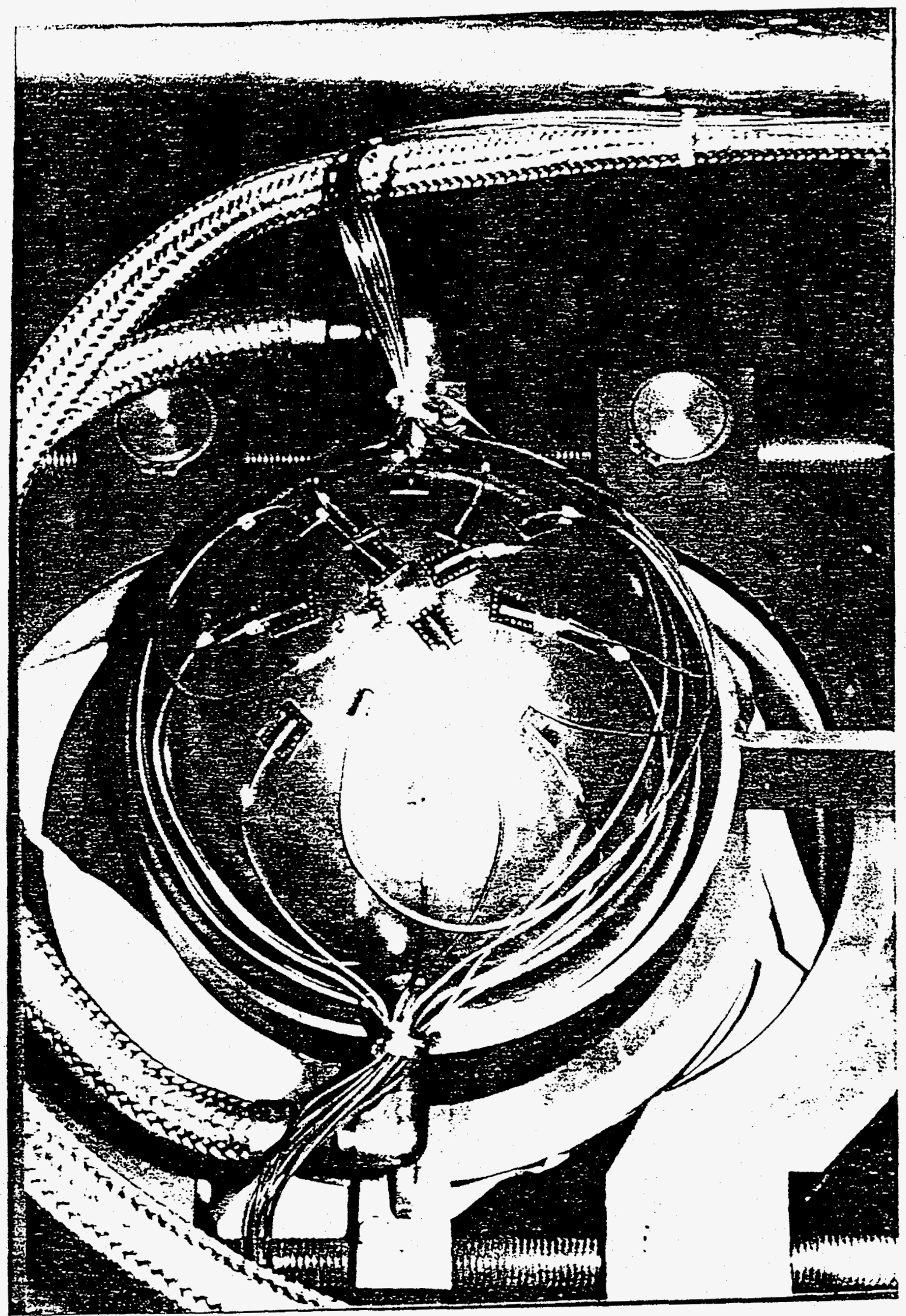

